\title{
Study Of The C677T and 1298AC Polymorphic Genotypes Of MTHFR Gene And Phenotype Genotype Correlation In Autism Spectrum Disorder
}

\author{
Farida El-baz, Mohammed. A .Mohammed, Tarek. M. Kamal, Abdelrahim A Sadek
} , Amr.Ahmed.Othman

\begin{abstract}
Background: Autism is currently known as "a behaviorally defined syndrome" manifested as impairment in social communication, repetitive routines and restricted interests .Overall, there is an increased risk of ASDs associated with common mutations affecting the folate/methylation cycle.

Aim of the study: This study aimed at identification of the C677T and 1298AC polymorphic genotypes of MTHFR gene among a sample of Egyptian children with autism and to make a phenotype-genotype correlation for the autistic patients.

Subjects and methods: This case-control study included 31 children with autism and 39 children in a normal control group, the mean age of patients and control was comparable ( 4.5 years \pm 2) with more males predominance in both groups. Assessments by DSM-V-TR criteria, Stanford-Binet intelligence scale V and childhood autism rating scale (CARS) were done. Genotyping for MTHFR gene polymorphic loci C677T and 1298AC was performed on amplified DNA by PCR with subsequent reverse hybridization and restriction fragment length polymorphisms analysis.
\end{abstract}

\section{Results}

The relation between low birth weight and occurrence of autism was highly significant $(P<\mathbf{0 . 0 1})$. The delayed motor and social milestones showed a statistically highly significant difference in cases of autism compared to controls $(P<\mathbf{0 . 0 1})$. Heterozygosity for A1298C polymorphism was highest among patients (41.9\%) followed by $\mathbf{3 5 . 5 \%}$ mutant genotype CC and $\mathbf{2 2 . 6 \%}$ normal AA(wild ) type and . Allele $\mathrm{C}$ was detected in patients more than in control $(\mathbf{5 6 . 4 5 \%}$ vs. $\mathbf{1 1 . 5 4 \%})(P$ $<0.001)$. For C667T polymorphism, heterozygosity was also highest among patients $\mathbf{( 4 8 , 4 \%}$ ) followed by wild type genotypes C677 (38.7\%) and 12,9\% for mutant genotypes 667T. Allele T appeared more in patients than control (31.10 \% vs. 5.13\%) $(\boldsymbol{P}<\mathbf{0 . 0 0})$. Heterozygosity for CT and A-C genotypes were detected equally $(\mathbf{4 6 . 2 \%})$ among patients with severe autism (according to CARS).

\section{Conclusion}

There is a significant association between severity and occurrence of autism with MTHFR gene polymorphisms C677T and A1298C. Further studies are needed on larger scale to explore other genes polymorphisms that may be associated with autism to correlate the genetic basis of autism.

Keywords

- Autism; MTHFR gene; Polymorphism; Genotype-phenotype; Egyptian children

\section{Introduction}

Autism is a complex neuro developmental disorder with a combined genetic and environmental factors [1] The prevalence of PDD range between 4.5 and 59/10. 000, depending on the diagnostic criteria used in each study[2] with three to four fold higher incidence in males than in females [3]. Most recent studies report it to be increasing to $\mathbf{1 1 0 / 1 0 . 0 0 0}$, The increasing incidence may be actual or resulting from the use of broadened 
criteria in diagnosis [4]. Autism is currently defined as "a behaviorally defined syndrome manifested as impairment in social communication , repetitive routines and restricted interests. The term "Pervasive developmental disorders"(PDDs) refers to five conditions 1) autistic disorder, (2) Asperger's disorder, (3) Rett's disorder, (4) childhood disintegrative Disorder, and (5) PDD not otherwise specified [5] and [6]. Autism spectrum disorders are characterized by language impairment, restricted interests, stereotypic motor behaviors, hyperactivity, sensory disturbances and self injury [7]. It is also associated with seizure disorder[8], gastrointestinal disturbances [9] and autoimmune disorders in some patients [10] A dysfunctional Folate Methionine pathway has been identified in many individuals with autism, this pathway is crucial for DNA synthesis and methylation. The Methylene Tetrahydrofolate Reductase (MTHFR) gene codes for an essential enzyme in folate metabolism, the gene is located on chromosome $1 \mathrm{P} 36.3$ in humans[11] .There are DNA sequence variants ( genetic polymorphism) associated with MTHFR gene, two of the most investigated are C677T and A1298C as a single nucleotide polymorphisms (SNP) [11].

The present study aimed at identification of possibly existing C677T and A1298C polymorphisms within MTHFR gene among an Egyptian sample of patients with autism and study of possible phenotype- genotype correlation.

\section{Patients and methods}

\subsection{Patients}

Seventy children were included in this case-control study and divided into two groups: patients group (31) with an age range 1.5 to $18(4.57 \pm 2)$ years and were diagnosed as autism by DSM-V-TR criteria(12) at
Psychiatric Clinic Pediatrics Hospital, Ain Shams University and Psychiatry Clinic Pediatrics Department Sohag University Hospital. Exclusion criteria included patients with suspected genetic, metabolic or chronic disease . Control group included 39 children not suffering from any psychiatric or behavioral problems with matched age and sex.

All of the patients were subjected to the following: Detailed history taking with special emphasis on onset, course and duration of the disease, consanguinity of the parents, antenatal, natal and postnatal history. Developmental history including mental, language, social and motor development. Family history of any similar condition and other psychological or mental disorders in the family. Thorough clinical examination with special emphasis on neurological examination. Genotyping consents from all patients' and controls' parents/guardians were taken to approve sharing in the study after full description of the steps and aim of the study. The work has been carried out in accordance with the code of Ethics of the World Medical association (Declaration of Helsinki) for experiments involving humans and the Ethical Committee of Ain Shams University" for the same purpose.

\subsection{Methods}

Confirmation of diagnosis using DSMV-TR criteria of autism [12] . Intelligence quotient (IQ) was evaluated by use of Stanford-Binet Intelligence Scales V[13]. The SBV can be administered to individuals as early as two years of age. There are ten subtests included in this revision including both verbal and nonverbal domains. Five factors are also incorporated in this scale, which are directly related to Cattell-HornCarroll (CHC) hierarchical model of cognitive abilities. These factors include 
fluid reasoning, knowledge, quantitative reasoning, visual-spatial processing, and working memory .

Assessment of severity of autistic symptoms was done using childhood autism rating scale ( CARS),[14]which rate the child on a scale from one to four in each of fifteen areas (relation to people, emotional response, imitation, body use, object use, listening response, fear or nervousness, verbal communication, non verbal communication, activity level and consistency of intellectual response, adaptation to change, visual response, taste, smell, touch response and general impression). The test divided patients according to severity as not autistic ( 15- 30); Mild or moderate autistic (30 39); severe autistic (39-60) .

Genotyping of methylene tetra hydrofolate reductase (MTHFR) gene polymorphism C677T was performed on DNA samples based on polymerase chain reaction (PCR) and reverse hybridization and subsequent conjugation using the streptavidinalkaline phosphatase. (MTHFR Stripassay $\left.{ }^{\mathrm{TM}}\right)$, Vienna lab diagnostics ${ }^{\circledR}$ $\mathrm{GmbH}$, Vienna, Austria).

Allele specific amplification was done for 1298AC polymorphism using PCRRFLP analysis as described elsewhere [15] and [16]

The restriction fragment length polymorphism (RFLP) was done by using a restriction enzyme MboII (Sibzyme ${ }^{\mathrm{TM}}$, Russia )
The PCR products were all documented by Gel Documentation System and Software for DNA analysis (InGenius Syngene ${ }^{\mathrm{TM}}-\mathrm{UK}$ ). Amplified DNA from a patient homozygous for the $1298 \mathrm{~A}$ allele appeared at a band length of $\mathbf{1 7 6} \mathrm{bp}$ in length compared to the size marker, with three smaller fragments of $\mathbf{3 0 , 2 8}$, and 22 bp. Presence of the A1298C polymorphism abolishes an MboI cut site; thus, DNA from a patient homozygous for the $1298 \mathrm{C}$ allele appeared at a band length of $204 \mathrm{bp}$ with smaller fragments of $\mathbf{3 0}$ and $\mathbf{2 2}$ bp Statistical analysis: The distribution of genotypes and allele frequencies were all statistically compared in all patients versus healthy controls. The results were analyzed using the Statistical Package of Social Sciences (SPSS) computer software program, version 11.0 (Chicago, IL, USA). Qualitative data were presented in the form of frequencies and percentages. Quantitative data were presented as mean \pm SD for normally distributed data and as medians and percentiles for skewed data. For Qualitative data, differences among groups were tested using Pearson's chi-square test $(X 2)$. A $P$ value less than $\mathbf{0 . 0 5}$ was considered statistically significant. For normally distributed parameters, differences among groups were tested by the $t$ test and a one-way analysis of variance

(ANOVA).

\section{Results}

Incidence of consanguinity among patients and control group was comparable

$(\mathbf{8 0 . 6 \%}$ vs. 84,6\%) which was statistically not significant $(P=\mathbf{0 . 6 6 1})$.

Compared to control group, family history of autism (9.7\%), epilepsy (16.1\%), prematurity $(\mathbf{9 . 7 \%})$ was detected among patients group $(\mathbf{P}<\mathbf{0 . 0 5})$.

Mean birth weight among patient group was less compared to the control group $(\mathbf{2 . 6 7} \pm \mathbf{0 . 3 8 9}$ vs.3.03 $\pm \mathbf{0 . 3 0 9} \mathbf{~ k g})(\mathbf{P}<\mathbf{0 . 0 1})$.However, the mean of gestational age was statistically not significant $(\boldsymbol{P}=\mathbf{0 . 6 7 6})$. (Table 1$)$

Type of feeding and the mean age of weaning among patient group compared to the mean age of weaning in control group was statistically not significant $(\boldsymbol{P}=\mathbf{0 . 1 6 2}$ and $\mathbf{0 . 7 8 6}$ respectively). The developmental milestones in patients group were delayed 
in comparison to control group ( $\boldsymbol{P}=<\mathbf{0 . 0 0 0 1})$. The mean level of IQ score among patients ( 66.13 $\pm \mathbf{8 . 2 0})$ was lower than the mean level of IQ among controls $(96 \pm \mathbf{8 . 8})$

$(\mathbf{P}=<\mathbf{0 . 0 0 0 1})$ ( Table 1).

(Table 1) Characteristics of patients and controls included in the study .

\begin{tabular}{|c|c|c|c|c|}
\hline Consanguinity & $\begin{array}{l}\text { Patients NO } \\
(\%)\end{array}$ & $\begin{array}{l}\text { Control No. } \\
(\%)\end{array}$ & $\begin{array}{l}\text { Chi- } \\
\text { square*/t } \\
\text { test** }\end{array}$ & P Value \\
\hline Yes & $6(19,4 \%)$ & $6(15,4 \%)$ & \multirow{2}{*}{$0.192 *$} & \multirow[t]{2}{*}{$0.661(\mathrm{NS})$} \\
\hline No & $25(80,6 \%)$ & $33(84,6 \%)$ & & \\
\hline \multicolumn{5}{|l|}{ Family history of autism } \\
\hline Yes & $3(9,7 \%)$ & $\mathbf{0}(\mathbf{0 \%})$ & \multirow{2}{*}{ 3.943* } & \multirow{2}{*}{$0.047(\mathbf{S})$} \\
\hline No & $28(90,3 \%)$ & $39(100 \%)$ & & \\
\hline \multicolumn{5}{|l|}{ Family history of epilepsy } \\
\hline Yes & $5(16,1 \%)$ & $\mathbf{0}(\mathbf{0 \%})$ & \multirow[t]{2}{*}{ 6.774* } & \multirow[t]{2}{*}{$0.009(\mathrm{~S})$} \\
\hline No & $26(83,9 \%)$ & $39(100 \%)$ & & \\
\hline \multicolumn{5}{|l|}{ History of prematurity: } \\
\hline Yes & $3(9,7 \%)$ & $\mathbf{0}(\mathbf{0 \%})$ & \multirow[t]{2}{*}{ 3.943* } & \multirow[t]{2}{*}{$0.047(\mathbf{S})$} \\
\hline No & $28(90,3 \%)$ & $39(100 \%)$ & & \\
\hline \multicolumn{5}{|l|}{ Feeding } \\
\hline Breast & $20(64,5 \%)$ & $31(79.5 \%)$ & \multirow[t]{2}{*}{ 1.958* } & \multirow[t]{2}{*}{$0.162(\mathrm{NS})$} \\
\hline Artificial & $11(35,5 \%)$ & $8(20,5 \%)$ & & \\
\hline Mean gestational age (weeks) & $39 \pm 1.25$ & $39.1 \pm 0.5$ & $0.408 * *$ & $0.676(\mathrm{NS})$ \\
\hline Mean birth weight (kg) & $2.67 \pm 0.389$ & $3.03 \pm 0.309$ & $4.205 * *$ & 0.0001(HS) \\
\hline Mean age for sitting (month) & $8.5 \pm 1.1$ & $6.65 \pm 0.87$ & $7.653 * *$ & $<0.0001(\mathrm{HS})$ \\
\hline Mean age at weaning (year) & $1.59 \pm 0.3$ & $1.61 \pm 0.31$ & $0.273 * *$ & 0.786(NS) \\
\hline $\begin{array}{l}\text { Mean age at 1st spoken word } \\
\text { (year) }\end{array}$ & $2.6 \pm 0.69$ & $1.13 \pm 0.18$ & $11.553 * *$ & $<0.0001(\mathrm{HS})$ \\
\hline Mean level of IQ score & $66.13 \pm 8.20$ & $96 \pm 8.8$ & $14.654 * *$ & $<0.0001($ HS $)$ \\
\hline
\end{tabular}

(HS) Highly significant (S) Significant (NS) Not Significant

AC heterozygote genotype was highest among patients $\mathbf{( 4 1 . 9 \% )}$ ) followed by CC

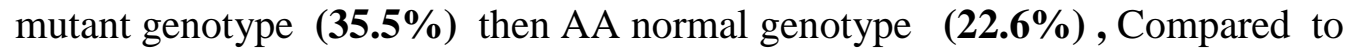
control group, where the most common polymorphism was AA normal genotype (79.5\%) $\quad(\mathbf{P}<0.001)$ (Table2)

The frequency of $\mathrm{C}$ allele was higher in patients $\mathbf{( 5 6 . 4 5 \% )}$ than controls $\mathbf{( 1 1 . 5 4 \% )}$ while A allele frequency in controls was more (88.46\%) than its frequency among patients $(\mathbf{4 3 . 5 5 \% )}(\mathrm{P}<\mathbf{0 . 0 0 1})$ (Table 2) 
(Table 2) A1298C genotype polymorphism and segregation of alleles among patients and control

\begin{tabular}{|c|c|c|c|c|}
\hline Group & patients & control & Chi square & P value \\
\hline AA genotype & $\begin{array}{l}7 \\
(22.6 \%)\end{array}$ & $\begin{array}{l}31 \\
(79.5 \%)\end{array}$ & \multirow{4}{*}{24.700} & \multirow{4}{*}{$<0.001$} \\
\hline AC genotype & $\begin{array}{l}13 \\
(41.9 \%)\end{array}$ & $\begin{array}{l}7 \\
(18 \%)\end{array}$ & & \\
\hline CC genotype & $\begin{array}{l}11 \\
(35.5 \%)\end{array}$ & $\begin{array}{l}1 \\
(2.5 \%)\end{array}$ & & \\
\hline Total & $\begin{array}{l}31 \\
(100 \%) \\
\end{array}$ & $\begin{array}{l}39 \\
(100 \%)\end{array}$ & & \\
\hline A-allele $(\mathrm{N}, \%)$ & $27(43.55 \%)$ & $69(88.46 \%)$ & \multirow{3}{*}{32.332} & \multirow{3}{*}{$<0.001$} \\
\hline C-allele (N, \%) & $35(56.45 \%)$ & $9(11.54 \%)$ & & \\
\hline Total & $62(100 \%)$ & $78(100 \%)$ & & \\
\hline
\end{tabular}

The most common $\mathbf{C 6 6 7}$ genotype among patient group was CT heterozygote while

in the control group, the most common genotype was the normal wild $\mathbf{C 6 6 7}$ genotype 35(89.8\%) (P<0.001)(Table 3)

The frequency $\mathrm{T}$ allele in patients was $(\mathbf{3 7 . 0 9 \%})$, that was more than its frequency in controls $(\mathbf{5 . 1 3 \%})$ and the frequency of $\mathrm{C}$ allele in control group $\mathbf{( 9 4 . 8 7 \% )}$ ) was more than its frequency among patients $(62.90 \%),(\mathbf{P}<0.001)($ Table 3).

(Table 3) Percentage of C667 genotypes and alleles among patients and control

\begin{tabular}{|c|c|c|c|c|}
\hline Group & Case & Control & Chi square & $P$ value \\
\hline $\begin{array}{l}\text { C667 } \\
\text { (Normal ) }\end{array}$ & $\begin{array}{l}12 \\
(38.6 \%)\end{array}$ & $\begin{array}{l}35 \\
(89.8 \%)\end{array}$ & \multirow{4}{*}{20.984} & \multirow{2}{*}{$<0.001$} \\
\hline $\begin{array}{l}\text { C667T } \\
\text { (Hetero) }\end{array}$ & $\begin{array}{l}15 \\
(48.4 \%)\end{array}$ & $\begin{array}{l}4 \\
(10.2 \%)\end{array}$ & & \\
\hline $\begin{array}{l}\text { 667T } \\
\text { (Mutant) }\end{array}$ & $\begin{array}{l}4 \\
(13 \%)\end{array}$ & $\begin{array}{l}0 \\
(0 \%)\end{array}$ & & \\
\hline Total & $\begin{array}{l}31 \\
(100 \%)\end{array}$ & $\begin{array}{l}39 \\
(100 \%)\end{array}$ & & \\
\hline $\begin{array}{l}\text { C allele } \\
\text { No. }(\%)\end{array}$ & $39(62.90 \%)$ & $74(94.87 \%)$ & & \\
\hline $\begin{array}{l}\text { T Allele } \\
\text { No. }(\%)\end{array}$ & $23(37.09 \%)$ & $4(5.13 \%)$ & 22.679 & $<0.001$ \\
\hline Total & $62(100 \%)$ & $78(100 \%)$ & & \\
\hline
\end{tabular}

CARS assessment mean value (38.091 \pm 4.721) in patients with CC mutant genotype of the polymorphic locus A1298C was more than CARS mean value (37.538 $\pm \mathbf{5 . 7 1 0}$ ) in patients with AC heterozygote genotype and CARS mean value $(\mathbf{3 5 . 8 5 7} \pm \mathbf{5 . 4 2 9})$ in patients with normal AA genotype, $(\mathbf{P}=\mathbf{0 . 6 8 0})$.

IQ mean value (69.571 \pm 7.35) in patients with normal AA genotype was higher than IQ mean value( 66.538 \pm 7.47) in patients with $\mathrm{A}-\mathrm{C}$ heterozygote and IQ mean value $(63.455 \pm 9.29)$ in patients with $C C$ mutant genotype, this was statistically not significant $(\mathbf{P}=\mathbf{0 . 3 0 6})$. Mean of DSM criteria(7.385 $\pm \mathbf{1 . 3 2 5})$ in patients with AC 
heterozygote was more than mean of DSM criteria(7.091 $\pm \mathbf{0 . 9 4 4 )}$ in patients with mutant CC genotype and mean of DSM criteria $(\mathbf{6 . 7 1 4} \pm \mathbf{0 . 4 8 8})$ in patients with normal AA genotype $(\mathbf{P}=\mathbf{0 . 4 0 9})$ ( Table 4$)$

(Table 4) Correlation between psychological assessment and A1298C genotype in patients.

\begin{tabular}{|l|l|l|l|}
\hline AC & CARS & IQ & DSM \\
\hline AA(Normal) & $35.857 \pm 5.429$ & $69.571 \pm 7.35$ & $6.714 \pm 0.488$ \\
\hline AC (Hetero) & $37.538 \pm 5.710$ & $66.538 \pm 7.47$ & $7.385 \pm 1.325$ \\
\hline CC (Mutant) & $38.091 \pm 4.721$ & $63.455 \pm 9.29$ & $7.091 \pm 0.944$ \\
\hline ANOVA & $\mathbf{0 . 3 9 1}$ & $\mathbf{1 . 2 3 6}$ & $\mathbf{0 . 6 8 0}$ \\
\hline P value & $\mathbf{0 . 6 8 0}$ & $\mathbf{0 . 3 0 6}$ & $\mathbf{0 . 4 0 9}$ \\
\hline
\end{tabular}

CARS assessment mean value (38.750 \pm 4.654) in patients with normal $\mathbf{C 6 6 7}$ was more than CARS mean value(37.500 $\pm \mathbf{5 . 6 8 6})$ in patients with mutant TT genotype and CARS mean value (36.200 $\pm \mathbf{5 . 5 7 0})$ in patients with $\mathrm{C}$ - $\mathrm{T}$ heterozygote genotype that was statistically not significant $(\mathbf{P}=\mathbf{0 . 4 6 4})$. IQ mean value $(\mathbf{6 5 . 7 5 0} \pm \mathbf{1 3 . 3 7 6})$ in patients with mutant TT genotype was lower than IQ mean of patients with normal and C-T heterozygote genotype, again this was statistically not significant $(\mathbf{P}=\mathbf{0 . 9 8 7})$. Mean value for DSM criteria in patients(7.333 $\pm \mathbf{1 . 0 7 3})$ with normal $\mathbf{C 6 6 7}$ genotype was more than mean value for DSM criteria among patients with mutant TT and heterozygote $\mathrm{C}-\mathrm{T}$ genotype that was statistically not significant $(\mathbf{P}=\mathbf{0 . 7 0 8})$ (Table 5 )

(Table 5) Correlation between psychological assessment and C667genotype

\begin{tabular}{|l|l|l|l|}
\hline C667 & CARS & IQ & DSM \\
\hline C667 (normal) & $38.750 \pm 4.654$ & $\mathbf{6 6 . 4 1 7} \pm 7.810$ & $7.333 \pm 1.073$ \\
\hline C667T (hetero) & $36.200 \pm 5.570$ & $66.000 \pm 7.606$ & $7.000 \pm 1.134$ \\
\hline 667T (mutant) & $37.500 \pm 5.686$ & $65.750 \pm 13.376$ & $7.000 \pm 0.817$ \\
\hline ANOVA & $\mathbf{0 . 7 9 0}$ & $\mathbf{0 . 0 1 3}$ & 0.350 \\
\hline P value & $\mathbf{0 . 4 6 4}$ & $\mathbf{0 . 9 8 7}$ & $\mathbf{0 . 7 0 8}$ \\
\hline
\end{tabular}

\section{Discussion}

There is an agreement that autism is a neuro developmental disorder characterized by impaired social interaction [17], which is usually diagnosed before the age of three years, and is characterized by deficits in language skills and social reciprocity that are associated with repetitive behaviors and restricted interests [18].

In our study, the mean age of patients and control was comparable ( 4.5 years \pm 2 ) with male patients more than females in both groups. This is in agreement with other studies[16 and 19].
In our study, non consanguinity constituted $\mathbf{8 0 . 6 \%}$ of the studied families compared to $\mathbf{8 4 , 6 \%}$ in the control group. Similar studies reported that the rate of consanguinity is lower among parents of patients with autism than in normal controls [20-24]. This may suggest that consanguinity has no role in autism.

In the current study, family history of autism was significantly higher in patients compared to control. This is in agreement with El Baz et al., [23], who reported that family history of 
autism was reported in $\mathbf{1 6 \%}$ of autistic patients versus $1 \%$ among the control .We found also that family history of epilepsy among patient group was significantly higher than control group.

In this study, history of low birth weight and prematurity was found to be significant among autistic children than controls. Kolevzon et al., [25] , suggested the presence of non heritable prenatal and perinatal risk factors for autism. An association is suggested between autism and obstetric complications, prenatal or intra partum use of medications[26]. A significantly higher incidence of low birth weight and using instrumental tools during delivery was reported among cases with autism than controls [23] . Perinatal risk factors such as breech presentation, low Apgar score, low birth weight $(2500 \mathrm{~g})$, gestational age at birth of less than 35-37 weeks, and being small for gestational age were associated with a statistically significant increased risk of autism[27]. In 2007, a review of risk factors demonstrated associated obstetric conditions that included low birth weight, gestation duration and hypoxia during childbirth with autism. Studies focusing on single perinatal risk factor have reported a positive association for low birth weight $(<2500 \mathrm{~g})$, and gestational age at birth of less than $\mathbf{3 7}$ weeks[28]

In our study, all developmental and social milestones were significantly delayed among autistic children compared to the control group. This is in agreement with Juneja et al., [29] who reported about $\mathbf{9 6 \%}$ of autistic children had motor developmental delay and qualitative impairment in social interaction and communication was also more commonly observed than restricted interests and activities . Children with autism may be delayed in acquiring motor activity, such as bicycle riding. They may be poorly coordinated or have an abnormal gait or posture and poor hand writing [30] Some of the noted behaviors in autism include delayed speech and language skills, and not to point or wave "byebye" [ 31]

In our study the patients mean IQ revealed a wide range from mild to severe mental retardation which was lower than mean IQ among control group This is in agreement with previous reports[ 20],

C667T polymorphism genotyping was consistent with the study of Elif et al. [19], that revealed the heterozygote 667CT as the most prevalent genotype among patients .

Our study findings were in agreement also with Shawky et al ., [20] who reported that homozygote mutant 677TT genotype was present in $15 \%$ of the autistic children while the heterozygous 677CT genotype occurred in $\mathbf{5 0 \%}$ of the autistic children group.Boris et al .,[ 16] reported that 677CT polymorphisms, whether homozygous or heterozygous, are significantly associated with ASD. In their study heterozygote CT genotype was more prevalent than mutant TT genotype, this is similar to our study but with different frequencies.

As regards the A1298C polymorphism, our study revealed that the most common polymorphism in patients group was AC heterozygote genotype followed by $\mathrm{CC}$ mutant then AA normal genotypes, in comparison to control group ,the most common polymorphism was AA normal genotype $\quad(\mathbf{P}<\mathbf{0 . 0 0 1})$. These findings were consistent with Boris et al.,[ 16], who reported that AC heterozygote genotype is the most prevalent among patients but in their study the mutant CC genotype in patients $(6 \%)$ was lesser than ours. The same authors reported that homozygous

(TT) 
individuals have an approximately $\mathbf{5 0 \%}$ decrease in MTHFR enzyme activity, the heterozygous (CT) have a $\mathbf{3 0 \%}$ decrease in enzyme activity as measured in their lymphocytes and the compound heterozygous state, 677CT/ 1298AC lower enzyme activity by 50 $\mathbf{- 6 0 \%}$. They reported also that, 1298AA normal alleles were more prevalent in the control population than in children with ASD. This is similar to control group in our study.

Our results also agree with Liu et al.,[ 32], regarding the frequency of $T$ allele among patients compared to control group.

It was reported that frequency of the heterozygous 677CT genotype in the ASD group $\mathbf{( 4 7 . 8 \% )}$ ) did not differ from that in the controls $(\mathbf{4 3 . 2 \%})$ [32] .This differs from our study where heterozygote 677CT genotype in ASD group was more prevalent than control group .

CARS mean value among patients group with normal (wild type) AA genotype was lower than that of patients with $\mathrm{AC}$ heterozygote and $\mathrm{CC}$ mutant genotypes with no significant difference $(\mathrm{P}=\mathbf{0 . 6 8 0})$. Again mean value for IQ in patients with normal (wild type) AA genotype was higher than IQ mean of patients with AC heterozygote and CC mutant genotype with no significant difference. $\quad(\mathbf{P}=\mathbf{0 . 3 0 6})$. This may indicate that there is no significant correlation between CARS (degree of severity of autism), IQ and A1298 polymorphisms. However, multicenter studies and larger samples size are needed to confirm such suggestion.

The C-T heterozygote genotype is more prevalent than other MTHFR C667 genotypes among patients with mild to moderate autism and patients with severe autism with no significant difference. CARS mean value in patients with normal $\mathbf{C 6 6 7}$ was more than CARS mean value in patients with mutant TT genotype and C-T heterozygote genotype, with no significant difference. IQ mean in patients with mutant TT genotype was lower than IQ mean of patients with normal and C-T heterozygote genotype with no significant difference.

These findings were in agreement with Shawky.,et al [20], who reported similar results with no significant difference for correlation between CARS and different genotypes for the same polymorphic alleles.

\section{References}

1. A.E. Main, M.T. Angley, P. Thomas, M. Fenech Folate and methio nine metabolism in autism Am J Clin Nutr, 91 (2010), pp. 1598-1620

2. Petersen D.J, N. Bilenberg and K.Hoerder et al., The population prevalence of child psychiatric disorders in Danish 8-to 9-year old children. Eur Child Adolese Psychiatr, 15 (2006),pp. 71-78.

3. M.G. Butler, M.J. Dasouki, X.-P. Zhou, Z. Talebizadeh, M. Brown, T.N. Takahashi, et al.Subset of individuals with autism spectrum disorders and extreme macrocephaly associated with germline PTEN tumor suppressor gene mutations

4. K.J. Davis SIG 16 perspectives on school-based issues ASHA, 15 (1) (2014), pp. 1-6

5. C. Abha, C. Ved. Review oxidative stress in autism Pathoph ysiology, 13 (2006), pp. 171-181

6. B.M. Kuehn Studies probe autism anatomy, genetics $\mathrm{J}$ Am Med Assoc (JAMA), 295 (2006), pp. 19-20

7. D.F. MacFabe, N.E. Cain, F. Boon, et al.Effects of the enteric bacterial metabolic product propionic acid on object-directed behavior, social behavior, cognition, and neuroinflammation in adolescent rats: Relevance to autism spectrum disorder 
Behav Brain Res, 217 (2008), pp. 4754

8. F.M.C. Besag . Behavioral aspects of pediatric epilepsy synd romes Epilepsy Behav, 5 (2004), pp. S3-S13

9. J.F. White . Intestinal pathophysiology in autism Exp Biol Med (Maywood), 228 (6) (2003), pp. 639-649

10. P. Ashwood, J. Van de Water Is autism an autoimmune disease? Autoimmune Rev, 3 (7-8) (2004), pp. 557-562

11. Schwahn B, Rozen $R$ methylenetetrahy drofolate reductase gene: clinical consequences". American Journal of Pharmacogenomics (2001). 1 (3): 189_ 201.

12. American Psychiatric Association. Diagnostic and Statistical Manual of Mental Disorders (DSM-V). 5th Edition. Washington, DC: American Psychiatric Association; 2013.

13. Stanford-Binet intelligence scales (SB-5), two years to adult 2003; fifth ed.

14. E. Schopler, R.J. Reichler, B.R. Renner. The childhood autism rating scale (CARS) for diagnostic screening and classification of autism, Irvington, New York (1986)

15. Hanson Q Naomi, Ömer Aras1, Feng Yang1 et al., C677T and A1298C Polymorphisms of the Methylenetetrahydrofolate Reductase Gene: Incidence and Effect of Combined Genotypes on Plasma Fasting and Post-Methionine Load Homocysteine in Vascular Disease.The American Association for Clinical Chem istry (2001)

16. Boris Marvin, M.D.; Allan Goldblatt, P.A.; Joseph Galanko et al., association of MTHFR gene variant with autism Ph.D. journal of american physicians and surgeons volume 9 no 42004

17. P.M. Kidd Autism, an extreme challenge to integrative medicine. Part
I: The knowledge base Alternat Med Rev, 7 (2002), pp. 292-316

18. I.M. Eigsti, T. Shapiro A system's neuroscience approach to autism: biological, cognitive and clinical perspectives Ment Retard Dev Disabil Res Rev, 9 (2003), pp. 205-215

19. Elif, F. S, Didem, B. O, and Yusuf, O. MTHFR Gene C677T Polym orphism in Autism Spectrum Disorders. Genetics Research International .Volume 2014 (2014)

20. Shawky Rabah. M, Farida El-baz , Tarek M. Kamal., et al. Study of genotype-phenotype correlation of methylene tetrahydrofolate reductase (MTHFR) gene polymorphisms in a sample of Egyptian autistic children Egyptian Journal of Medical Human Genetics .Volume 15, Issue 4, October 2014, Pages 335-341

21. H. Elshahawi, N. Shaker, H. Essawy, A. Eissaa, H. Sadek, A. Haroon. Risk factors and clinical presentations of autism in an Egyptian sample. Egypt $\mathbf{J}$ Neurol Psychiat Neuro surg, 44 (1) (2007), pp. 69-77

22. D. Bilder, P.Z. Judith, M. Judith, M. William.Prenatal, perinatal and neonatal factors associated with autism spectrum disorders Pediatrics, 123 (2009), p. 1293

23. F. El-Baz, N.A. Ismael, S.M. Nour El-Din Risk factors for autism: an Egyptian study Egyptian J Med Hum Genet, 12 (2011), pp. 31-38

24. A.M. Salem, S. Ismail, W.A. Zarouk, O. Abdul Baky, A.A. Sayed, S. Abd El-Hamid, et al.Genetic variants of neurotransmitter-related genes and miRNAs in Egyptian autistic patients Sci World J, 2013 (2013), pp. 1-7

25. Kolevzon A , R. Gross, A. Reichenberg. Prenatal and perinatal risk factors for autism: a review and integration of findings. Arch Pediatr Adolesc Med, 161 (4) (2007), pp. 326-333. 
26. Bolton $\mathrm{P}$, A. Pickles, R. Harrington, et al. Season of birth: issues, approaches and findings for autism .J Child Psychol Psychiatry, 33 (1992), pp. 509-530

27. Burd L, R. Severud, J. Kerbeshian, M. Prenatal and perinatal risk factors for autism. J Perinat Med, 27 (6) (1999), pp. 441-450.

28. Limperopoulos C, H. Bassan, K. Gauvreau, R.L et al., Does cerebellar injury in premature infants contribute to the high prevalence of long-term cognitive, learning, and behavioral disability in survivors? Pediatrics, 120 (2007), p. 584

29. Juneja M, S.B. Mukherjee, S. Sharma. A descriptive hospital based study of children with autism. Indian Pediatr, 42 (5) (2005), pp. 453-458
30. McPartland P.J, A. Klin. Asperger"s syndrome .Adolesc Med Clin, 17 (3) (2006), pp. 771-788.

31.Filipek P.A , P.J. Accordo, G.T. Baranek. The screening and diagnosis of autistic spectrum disorders. J Autism Dev Disord, 29 (6) (1999), pp. 439-484.

32. Liu X , F. Solehdin, I. L. Cohen et al., "Population- and family-based studies associate the MTHFR gene with idiopathic autism in simplex families," Journal of Autism and Developmental Disorders, vol. 41, no. 7, pp. 938-944, 2011. 